\title{
O desmame precoce afeta o ganho de peso e a composição corporal em camundongos adultos?
}

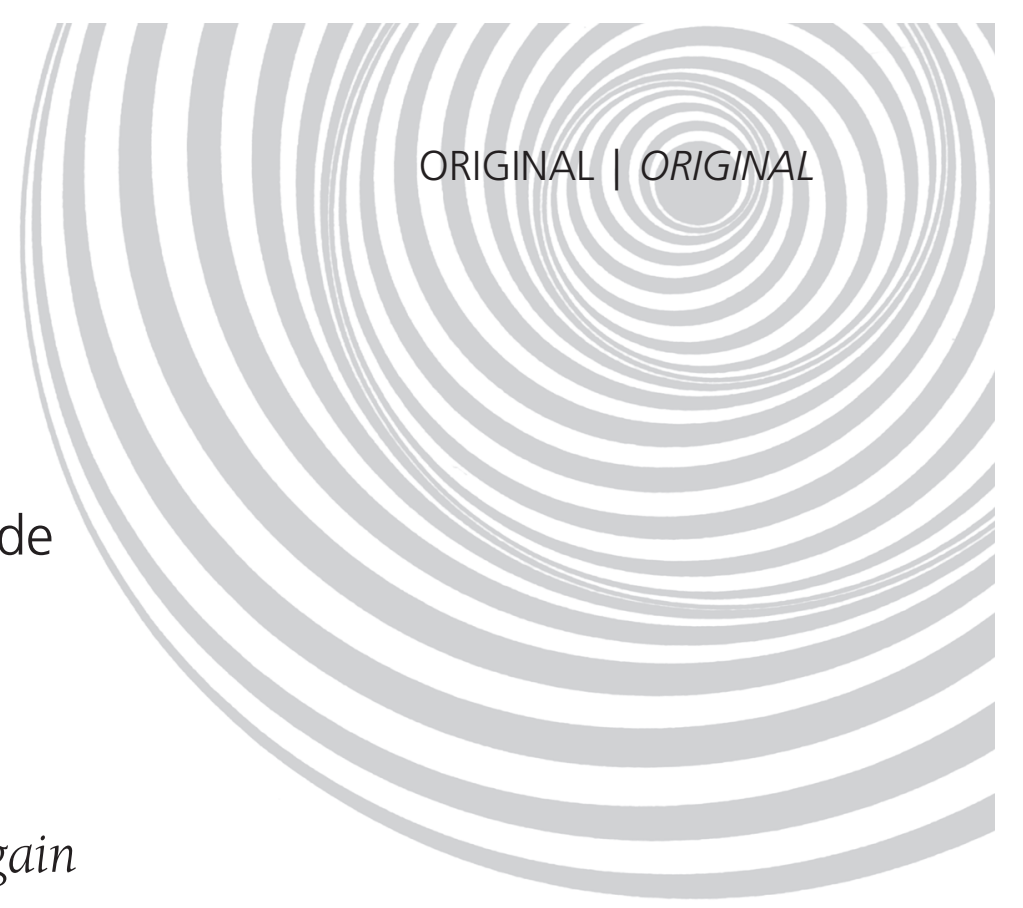

\section{Does early weaning influence weight gain and body composition in adult mice?}

Marcelo Macedo ROGERO'

Maria Carolina BORGES'

Ivanir Santana de Oliveira PIRES ${ }^{1}$

Julio TIRAPEGUI'

\section{RE S U M O}

\section{Objetivo}

Avaliar o efeito do desmame precoce sobre o ganho de peso e a composição corporal de camundongos adultos jovens.

\section{Métodos}

Camundongos Swiss Webster, machos, foram desmamados precocemente ( $14^{\circ}$ dia de vida) ou amamentados até o $21^{\circ}$ dia de vida (grupo controle). Após o desmame, os animais foram alimentados com ração elaborada para roedores em crescimento até o $63^{\circ}$ dia de vida, quando então foram sacrificados.

\section{Resultados}

O peso corporal dos animais do grupo desmamado de forma precoce foi significantemente maior no $28^{\circ}, 35^{\circ}$ e no $63^{\circ}$ dias de vida em relação ao grupo controle $(p<0,05)$. Porém, o consumo de ração não diferiu entre os grupos. A concentração sérica de proteínas totais, albumina e ferro, bem como a concentração hepática, muscular e cerebral de proteínas, ácido desoxirribonucléico e a relação proteína/ácido ribonucléico, não diferiram significantemente entre os grupos. O grupo desmamado precocemente apresentou maior quantidade absoluta de massa magra, lipídeos, proteínas e cinzas, em comparação ao grupo controle $(p<0,05)$. A quantidade relativa de umidade, lipídeos, massa magra, proteínas e cinzas não diferiu entre os grupos.

\section{Conclusão}

O desmame precoce, associado à ingestão de ração elaborada para roedores em crescimento, resultou em aumento do ganho de peso, porém não afetou a composição corporal de camundongos adultos.

Termos de indexação: Aleitamento materno. Camundongos. Composição corporal. Consumo alimentar. Desmame precoce.

\footnotetext{
1 Universidade de São Paulo, Faculdade de Ciências Farmacêuticas, Departamento de Alimentos e Nutrição Experimental Laboratório de Bioquímica da Nutrição. Av. Prof. Lineu Prestes, 580, Bloco 14, 05508-900, São Paulo, SP, Brasil. Correspondência para/Correspondence to: J. TIRAPEGUI. E-mail: <tirapegu@usp.br>.
} 
86 | M.M. ROGERO et al.

\section{A B S T R A C T}

\section{Objective}

The objective of this study was to assess the effect of early weaning on weight gain and body composition of young adult mice.

\section{Methods}

Swiss Webster male mice were weaned early, on the $14^{\text {th }}$ day of life, or breastfed until the $21^{\text {st }}$ day of life (control group). After weaning, the animals were fed a chow specifically made for growing rodents up to the $63^{\text {rd }}$ day of life, when they were sacrificed.

\section{Results}

The body weight of the animals from the early-weaned group was significantly greater on the $28^{\text {th }}, 35^{\text {th }}, 63^{\text {rd }}$ days of life compared to those from the control group $(p<0.05)$. Nevertheless, no significant difference in the food intake between the groups was observed. The concentration of serum total proteins, albumin and iron, as well as the concentration of protein, DNA and the protein/RNA ratio in the liver, muscle and brain, did not differ between the groups. The early-weaned group showed an increased absolute quantity of lean mass, lipids, protein and ash compared with the control group $(p<0.05)$. The relative quantity of water, lipids, lean mass, protein and ash did not differ between the groups.

\section{Conclusion}

Early weaning, associated with the consumption of a chow specifically made for growing rodents, led to an increase in weight gain, but did not influence body composition in adult mice.

Indexing terms: Breastffeeding. Mice. Body composition. Food consumption. Weaning.

\section{N T R O D U ÇÃ O}

A obesidade é considerada um problema de saúde pública em países desenvolvidos e em alguns países em desenvolvimento ${ }^{1,2}$. Crianças e adolescentes com excesso de peso têm maior risco de apresentar sobrepeso e obesidade na idade adulta, independentemente da presença de obesidade nos pais ${ }^{3,4}$. Aliado a isso, esses indivíduos, quando adultos, são mais suscetíveis a desenvolver doenças crônicas não transmissíveis, a exemplo das enfermidades cardiovasculares ${ }^{5}$. Uma vez que intervenções direcionadas à redução de peso para essa população não são satisfatoriamente efetivas, a identificação de estratégias visando à prevenção do excesso de peso na infância e na adolescência é de extrema importância na diminuição, a longo prazo, da incidência de doenças crônicas não transmissíveis ${ }^{6,7}$.

Conjuntamente ao impacto da amamentação sobre o estado nutricional e sobre a imunocompetência de roedores e de seres humanos ${ }^{8-12}$, há evidências de um possível papel do aleitamento materno na prevenção do sobrepeso e da obe- sidade na infância e na adolescência. Nesse contexto, bebês amamentados têm maior capacidade de autorregulação da ingestão energética em relação a bebês que recebem alimentação complementar precocemente ${ }^{13,14}$. Além disso, neonatos alimentados artificialmente apresentam picos maiores e mais prolongados de secreção de insulina no período pós-prandial em relação a bebês amamentados, o que, possivelmente, ocasiona maior estímulo à deposição de proteínas e de lipídeos, influenciando na composição corporal dessa população ${ }^{15-17}$.

Cabe ainda destacar que o leite materno contém hormônios e fatores de crescimento, como a leptina e o Fator de Crescimento Epidermal (EGF), os quais podem influenciar na adiposidade por meio da diminuição da ingestão alimentar e do aumento do gasto energético e pela inibição da diferenciação de adipócitos e da redução do acúmulo de lipídeos nessas células, respectivamente ${ }^{18-20}$. Desse modo, o desmame precoce e a consequente privação desses compostos presentes no leite materno podem ter influência sobre o 
risco de desenvolver obesidade na idade adulta $^{21-25}$.

Apesar de o efeito protetor do aleitamento materno em relação à adiposidade ser biologicamente plausível, os resultados obtidos em estudos epidemiológicos são inconsistentes. Alguns estudos concluem que o aleitamento materno protege contra o sobrepeso e a obesidade na infância e na adolescência ${ }^{26-29}$, ao passo que outros não encontraram associação entre essas variáveis ${ }^{30-32}$. Somam-se a esse fato a escassez de estudos longitudinais, bem como a dificuldade de estabelecer uma relação causal entre o aleitamento materno e a obesidade, visto que diversos são os fatores de confusão que interferem nessa associação, dentre os quais se destacam os aspectos socioeconômicos ${ }^{33-35}$.

Em virtude da ampla diversidade de fatores que permeiam a relação entre aleitamento materno, crescimento e ganho de peso, estudos observacionais que investigam os benefícios do aleitamento materno apresentam muitos problemas metodológicos. Idealmente, seriam necessários estudos randomizados para avaliar a relação entre desmame precoce e adiposidade. Não obstante, por razões éticas, este tipo de estudo é apenas realizado em animais ${ }^{35}$. Ademais, a maior parte dos estudos que investigou a associação entre aleitamento materno e excesso de peso utilizou o Índice de Massa Corporal (IMC) para a idade como preditor de adiposidade. No entanto, uma vez que esse índice não diferencia a massa gorda e a massa magra, não está bem estabelecido o efeito da introdução precoce de alimentos complementares sobre a composição corporal desses indivíduos. Sendo assim, o objetivo deste estudo foi avaliar o efeito do desmame precoce sobre o ganho de peso e a composição corporal de camundongos adultos jovens.

\section{MÉ T O D O S}

Foram utilizados camundongos Swiss Webster, machos, desmamados no $14^{\circ}$ e no $21^{\circ}$ dias de vida, obtidos de colônias de produção e de experimentação da Faculdade de Ciências Farmacêuticas e do Instituto de Química da Universidade de São Paulo. Os animais foram mantidos sob condições ambientais controladas, temperatura de $22^{\circ} \mathrm{C}$, com variação de $2^{\circ} \mathrm{C}$, umidade relativa de $55 \%$, com variação de $10 \%$ e ciclo de iluminação $12 \mathrm{~h}$ claro/12h escuro (luz acesa às $7 \mathrm{~h}$ ). Os animais foram pesados diariamente, sendo verificado o peso final dos mesmos imediatamente antes do sacrifício. O ganho de peso em relação ao início do protocolo experimental $\left(14^{\circ}\right.$ dia de vida) foi calculado no $21^{\circ}, 28^{\circ}, 35^{\circ}, 42^{\circ}$, $49^{\circ}, 56^{\circ}$ e $63^{\circ}$ dias de vida, com base na fórmula: (peso $(\mathrm{g}) /$ peso inicial $(\mathrm{g})-1) * 100$.

Os animais foram obtidos a partir do acasalamento de duas fêmeas, de dois meses de idade e primíparas, com um macho. Após a constatação da prenhez, as fêmeas foram mantidas em gaiolas individuais durante todo o período de gestação. Após o nascimento dos filhotes, fez-se a sexagem dos neonatos para oito camundongos machos, que foram mantidos com a mãe durante o período de 14 ou de 21 dias de vida. De modo a igualar a ingestão de leite entre os filhotes, foram colocados sempre oito animais com cada mãe. Os animais amamentados até o $21^{\circ}$ dia de vida, período regular de Amamentação (AMAM) de camundongos, foram considerados como grupo controle, ao passo que os camundongos Desmamados (DESM) no $14^{\circ}$ dia de vida constituíram o grupo desmamado precocemente. Cabe destacar que os filhotes não tinham acesso à ração materna.

No momento do desmame $\left(14^{\circ}\right.$ ou $21^{\circ}$ dia de vida), os animais foram cuidadosamente retirados da gaiola na qual estava a mãe, e transferidos para gaiolas que continham a ração. No momento da introdução dos animais na nova gaiola, eles foram posicionados próximos à ração, visando a facilitar o seu reconhecimento e o seu consumo. Além disso, foram utilizados comedouros com abertura lateral, o que facilitou o acesso à ração por esses animais. No período entre o desmame e o $63^{\circ}$ dia de vida, os camundongos foram alimentados ad libitum com água e com 
ração elaborada para roedores em crescimento, de acordo com o American Institute of Nutrition ${ }^{36}$.

No $63^{\circ}$ dia de vida, os animais foram previamente anestesiados com cloridrato de quetamina (50mg/kg de massa corporal) associado ao cloridrato de xilazina (50mg/kg de massa corporal), por via intraperitonial, e só então sacrificados. 0 sacrifício foi realizado no período da manhã, entre 8 e 12 horas. O sangue foi coletado do plexo axilar para a obtenção do soro, a partir do qual foram determinadas as concentrações de proteínas totais, de albumina e de ferro. Posteriormente à coleta do sangue, o músculo gastrocnêmio, o fígado e o cérebro foram dissecados e imediatamente pesados e congelados a $-80^{\circ} \mathrm{C}$, para posterior determinação da concentração de proteína, de RNA (ácido ribonucléico) e de DNA (ácido desoxirribonucléico). A partir da carcaça dos animais, foi realizada a análise da sua composição química, ou seja, a quantificação de umidade, de proteínas, de lipídeos e de cinzas.

O cálculo do tamanho da amostra a ser utilizada foi efetuado com base em critério estatístico, sendo utilizados: a) 8 animais para a determinação dos parâmetros séricos e para a determinação da concentração tecidual de proteína, RNA e DNA; b) 13 animais para composição corporal; c) e 15 animais para os dados de peso corporal e de consumo de ração ${ }^{37}$. Todos os procedimentos realizados com os camundongos foram aprovados pelo Comitê de Ética sobre experimentação com animais da Faculdade de Ciências Farmacêuticas da Universidade de São Paulo, de acordo com as diretrizes do Colégio Brasileiro de Experimentação Animal (COBEA).

A concentração sérica de ferro e de albumina foi determinada segundo descrito por Goodwin et al. ${ }^{38}$ e Doumas ${ }^{39}$, respectivamente. A concentração sérica de proteínas totais foi dosada por método colorimétrico, utilizando-se kit comercial (CELM, São Paulo, Brasil). Em relação aos parâmetros teciduais, a concentração de proteína no fígado, no músculo gastrocnêmio e no cérebro foi determinada em consonância com a metodologia descrita por Lowry et al. ${ }^{40}$. A determinação da concentração de RNA e de DNA desses tecidos foi realizada de acordo com o descrito por Munro $\&$ Fleck ${ }^{41}$ e por Gendimenico et al. ${ }^{42}$, respectivamente. O conteúdo de umidade, de lipídeos, de proteínas e de cinzas presentes na carcaça dos camundongos foi determinado segundo o descrito por Donato et al. ${ }^{43}$.

Os dados foram expressos como Média e Desvio-padrão (DP). Os resultados obtidos entre os grupos controle (AMAM) e o grupo desmamado precocemente (DESM) foram previamente analisados quanto à normalidade e submetidos ao Teste $t$ para variáveis independentes, adotando-se um valor de alfa de 0,05. Todos os cálculos foram realizados com auxílio do programa GraphPad Prism versão 4.0 .

RE S U L T A D O S

O peso dos animais ao nascimento não diferiu significantemente entre os grupos DESM $(1,55, D P=0,31 \mathrm{~g})$ e AMAM $(1,55, D P=0,27 \mathrm{~g})$.

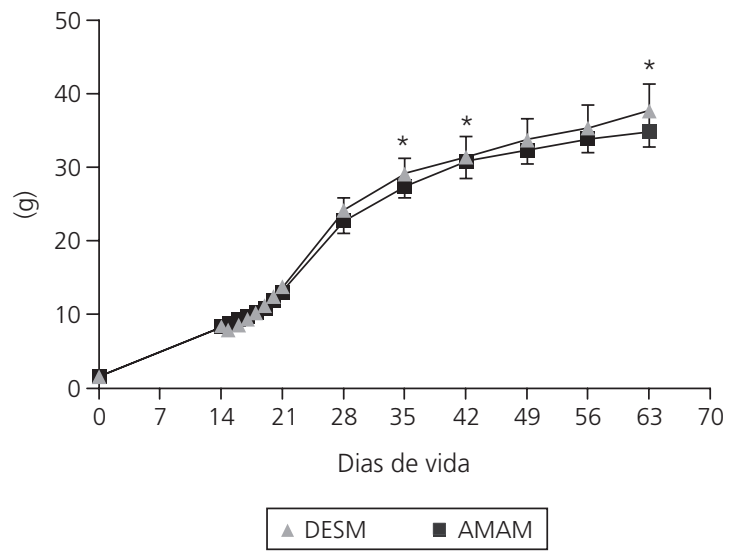

Figura 1. Curva de peso de camundongos amamentados até o $21^{\circ}$ dia de vida (grupo AMAM) ou desmamados no $14^{\circ}$ dia de vida (grupo DESM). São Paulo (SP), 2007-2008.

Nota: * $p<0,05$ em relação ao grupo AMAM na mesma idade, resultados expressos em média e desvio-padrão com $n=15 /$ grupo. 
No entanto, o peso corporal, bem como o percentual de ganho de peso dos animais do grupo DESM, foi significantemente maior no $28^{\circ}, 35^{\circ} \mathrm{e}$ $63^{\circ}$ dias de vida em relação ao grupo AMAM (Figuras 1 e 2). O consumo de ração absoluto e relativo não diferiu entre os grupos no período compreendido entre o $21^{\circ}$ e o $63^{\circ}$ dias de vida

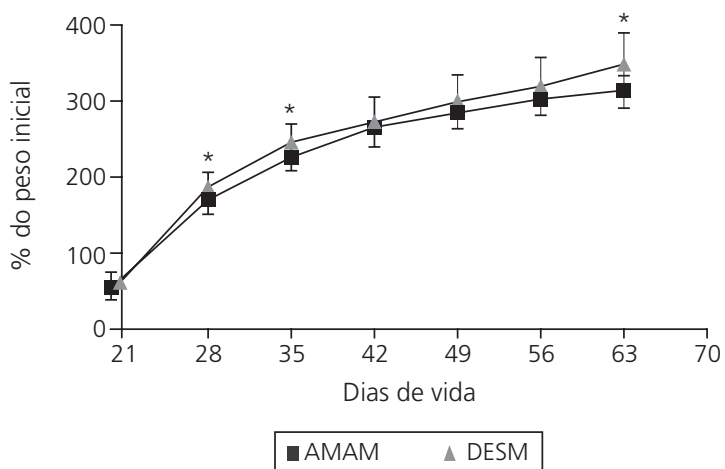

Figura 2. Curva de ganho de peso de camundongos amamentados até $021^{\circ}$ dia de vida (grupo AMAM) ou desmamados no $14^{\circ}$ dia de vida (grupo DESM). São Paulo (SP), 2007-2008.

Nota: * $p<0,05$ em relação ao grupo AMAM na mesma idade, resultados expressos em média e desvio padrão com $n=15 /$ grupo.

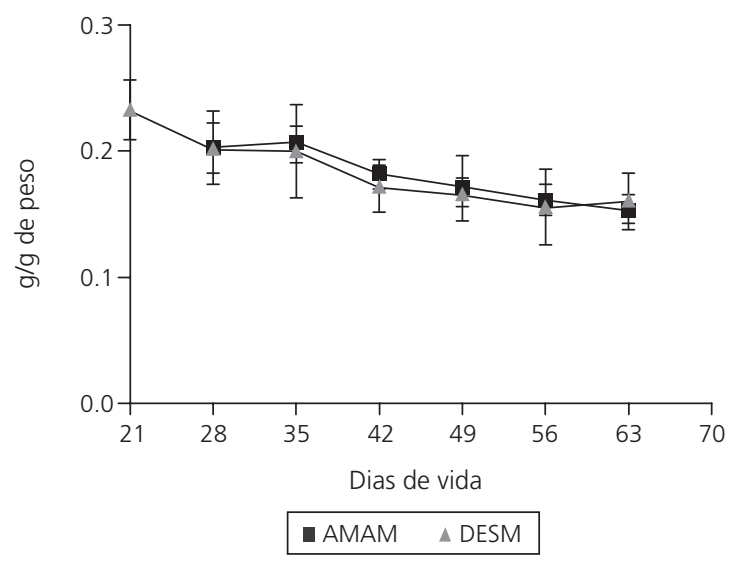

Figura 4. Consumo relativo de ração de camundongos amamentados até o $21^{\circ}$ dia de vida (grupo AMAM) ou desmamados no $14^{\circ}$ dia de vida (grupo DESM). São Paulo (SP), 2007-2008.

Nota: Resultados expressos em média e desvio-padrão com $n=15 / g r u p o$. Não houve diferença significante entre os grupos.
(Figuras 3 e 4). A concentração sérica de ferro, de albumina e de proteínas totais não diferiu entre os grupos. Também não foi observada diferença significante entre os grupos em relação à concentração de proteína e de DNA e à razão proteína/RNA no fígado, no músculo gastrocnêmio e no cérebro.

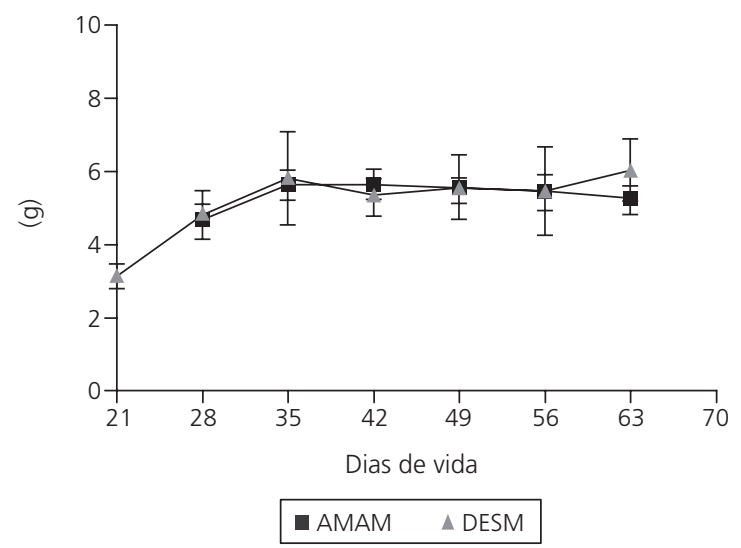

Figura 3. Consumo de ração de camundongos amamentados até o $21^{\circ}$ dia de vida (grupo AMAM) ou desmamados no $14^{\circ}$ dia de vida (grupo DESM). São Paulo (SP), 2007-2008.

Nota: Resultados expressos em média e desvio-padrão com $n=15 / g r u p o$. Não houve diferença significante entre os grupos.

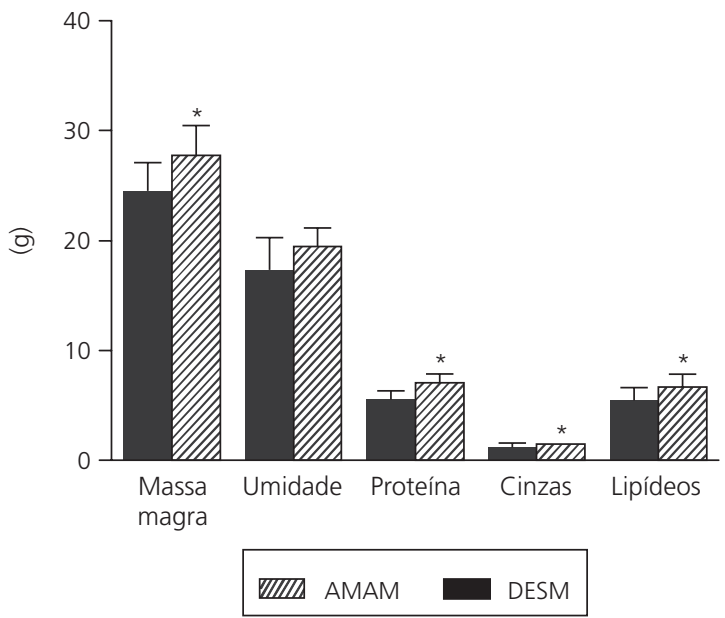

Figura 5. Valores absolutos da composição corporal de camundongos amamentados até o $21^{\circ}$ dia de vida (grupo AMAM) ou desmamados no $14^{\circ}$ dia de vida (grupo DESM). São Paulo (SP), 2007-2008.

Nota: * $p<0,05$ em relação ao grupo AMAM na mesma idade, resultados expressos em média e desvio-padrão com $n=13 /$ grupo. 
90 | M.M. ROGERO et al.

No que concerne à composição química da carcaça, o grupo DESM apresentou aumento significante da quantidade absoluta de massa magra, de lipídeos, de proteína e de cinzas (Figura 5). Contudo, não foi observada diferença significante na quantidade relativa de massa magra, de umidade, de lipídeos, de proteína e de cinzas entre os grupos experimentais.

\section{I S C U S S Ã O}

Este estudo avaliou o efeito do desmame precoce a partir do $14^{\circ}$ dia de vida dos animais, sendo que o período total de amamentação de camundongos é de 21 dias. A escolha da data de desmame foi devida ao fato de, em um estudo piloto, ter sido verificado que camundongos desmamados com idade inferior a 14 dias de vida apresentavam elevada taxa de mortalidade nos dois a três dias posteriores ao desmame. Essa observação está relacionada, em parte, ao fato de a abertura dos olhos de camundongos recém-nascidos ocorrer em torno do $10^{\circ}-12^{\circ}$ dia de vida, o que dificulta a realização de um protocolo experimental em que o animal deva livremente ingerir a ração ofertada ${ }^{44}$. Sendo assim, foi avaliado neste estudo o efeito do desmame precoce em camundongos que foram desmamados após terem completado $2 / 3$ do período de amamentação habitual.

Em relação aos parâmetros indicativos do estado nutricional (concentração sérica de albumina, de proteínas totais e de ferro; concentração hepática, muscular e cerebral de proteína e de DNA e razão proteína/RNA), não foi observada diferença entre os grupos, o que sugere que os animais do grupo DESM não apresentaram prejuízo no estado nutricional no $63^{\circ}$ dia pós-natal. Isso, possivelmente, está relacionado ao fato de a ração oferecida ser especificamente elaborada para roedores em crescimento ${ }^{36}$. Essa ração tem como fonte protéica a caseína e é acrescida de cisteína, aminoácido limitante da caseína, o que possibilitou a manutenção do estado nutricional protéico dos animais do grupo DESM, em comparação àquele observado em animais amamentados durante 21 dias. Contudo, é relevante destacar que as determinações bioquímicas foram realizadas em animais com 63 dias de vida, ou seja, somente 49 dias após o desmame, fato que pode ter sido responsável por não terem sido observadas alterações nos parâmetros relativos ao estado nutricional.

Apesar de não ter sido constatada diferença significante entre os grupos nos parâmetros indicativos do estado nutricional, os animais do grupo DESM apresentaram aumento do peso corporal e do ganho de peso em relação aos animais do grupo AMAM. Uma vez que o consumo de ração não diferiu entre os grupos, a diferença observada na massa corporal entre os animais amamentados e os animais desmamados precocemente pode ser atribuída à presença de fatores não nutricionais presentes no leite materno, a exemplo da leptina e do EGF, bem como a diferenças na resposta endócrina à alimentação (insulinemia pós-prandial) ${ }^{15-25}$. Nesse contexto, Attig et al..$^{24}$ observaram que o tratamento com um antagonista da leptina entre o $2^{\circ}$ e o $13^{\circ}$ dia de vida resultou em um aumento significante do peso e da gordura corporal em ratos adultos. Aliado a isso, outro estudo demonstrou que a administração oral de doses fisiológicas de leptina durante o período de lactação $\left(1^{\circ}\right.$ ao $20^{\circ}$ dia de vida) preveniu o ganho de peso e a obesidade em ratos na idade adulta, mesmo quando esses animais foram submetidos à dieta hiperlipídica ${ }^{25}$.

O aumento da quantidade absoluta de massa magra, de lipídeos, de cinzas e de proteínas no grupo DESM, em relação ao grupo AMAM ocorreu como consequência do aumento da massa corporal, uma vez que não foi observada diferença significante nas quantidades relativas de massa magra, de lipídeos, de cinzas e de proteínas. Desse modo, é possível inferir que o desmame precoce alterou o ganho de peso, porém não teve influência sobre a composição corporal dos animais. 
Ademais, o presente estudo foi realizado em camundongos adultos jovens e, portanto, faz-se necessário investigar se o efeito do desmame precoce sobre a massa corporal persiste em fases mais avançadas da idade adulta ${ }^{21-25}$.

Uma vez que os resultados deste estudo indicam que, em camundongos, o desmame precoce resulta em aumento do peso corporal, o que é decorrente de um aumento não apenas da massa gorda, como também da massa magra, é possível que estes resultados reproduzam-se em seres humanos. Dessa forma, sugere-se que modelos antropométricos que avaliam separadamente massa gorda e massa magra sejam mais adequados para esclarecer o papel do aleitamento materno na redução do risco de sobrepeso e de obesidade. Além disso, destaca-se a necessidade de estudos que investiguem se os efeitos do desmame precoce sobre a massa corporal persistem na idade adulta.

\section{O N CLUS Ã O}

O desmame precoce, associado à ingestão de ração elaborada para roedores em crescimento, acarreta em aumento do ganho de peso de camundongos, porém não tem influência sobre sua composição corporal. Estes resultados indicam a necessidade de estudos futuros em humanos, que avaliem o efeito do desmame precoce sobre a composição corporal por meio da utilização de modelos antropométricos que diferenciem a massa gorda e a massa magra.

\section{A GRADECIMENTOS}

Ao apoio financeiro da Fundação de Amparo à Pesquisa do Estado de São Paulo - (processo 03/01606-8) e do Conselho Nacional de Desenvolvimento Científico e Tecnológico, Brasil.

\section{COLABORADORES}

M.M. ROGERO e M.C. BORGES participarm da concepção, do delineamento, da análise dos dados e da interpretação dos resultados deste estudo. I.S.O. PIRES participou da análise dos dados deste estudo. J. TIRAPEGUI participou da interpretação dos resultados deste estudo.

\section{REFERÊ N CIAS}

1. Wang $Y$, Lobstein T. Worldwide trends in childhood overweight and obesity. Int J Pediatr Obes. 2006; 1(1):11-25. doi: 10.1080/174771606 00586747.

2. Kelishadi R. Childhood overweight, obesity, and the metabolic syndrome in developing countries. Epidemiol Rev. 2007; 29: 62-76. doi: 10.1093/ epirev/mxm003.

3. Togashi K, Masuda H, Rankinen T, Tanaka S, Bouchard C, Kamiya H. A 12-year follow-up study of treated obese children in Japan. Int J Obes Relat Metab Disord. 2002; 26(6):770-7. doi: 10.1038/ sj.ijo.0801992.

4. Magarey AM, Daniels LA, Boulton TJ, Cockington RA. Predicting obesity in early adulthood from childhood and parental obesity. Int J Obes Relat Metab Disord. 2003; 27(4):505-13. doi: 10.1038/ sj.ijo.0802251.

5. Baker JL, Olsen LW, Sørensen TI. Childhood bodymass index and the risk of coronary heart disease in adulthood. N Engl J Med. 2007; 357(23): 2329-37. doi: 10.1016/j.jvs.2008.02.015.

6. Gibson LJ, Peto J, Warren JM, Santos Silva I. Lack of evidence on diets for obesity for children: a systematic review. Int J Epidemiol. 2006; 35(6): 1544-52. doi: 10.1093/ije/dyl208.

7. Snethen JA, Broome ME, Cashin SE. Effective weight loss for overweight children: a metaanalysis of intervention studies. J Pediatr Nurs. 2006; 21(1):45-56. doi: 10.1016/j.pedn.2005.06. 006.

8. Filteau SM. Role of breast-feeding in managing malnutrition and infectious disease. Proc Nutr Soc. 2000; 59(4):565-72. doi: 10.1017/S00296651000 0080X.

9. Hanson LA. Session 1: Feeding and infant development breast-feeding and immune function. Proc Nutr Soc. 2007; 66(3):384-96. doi: 10.1017/ S0029665107005654.

10. Rogero MM, Borelli P, Fock RA, Pires IS, Tirapegui J. Glutamine in vitro supplementation partly reverses impaired macrophage function resulting from early weaning in mice. Nutrition. 2008; 24(6): 589-98. doi: 10.1016/j.nut.2008.02.005.

11. Rogero MM, Borelli P, Vinolo MA, Fock RA, Pires IS, Tirapegui J. Dietary glutamine supplementation 
affects macrophage function, hematopoiesis and nutritional status in early weaned mice. Clin Nutr. 2008; 27(3):386-97. doi: 10.1016/j.clnu.2008.03. 004.

12. Rogero MM, Tirapegui J, Vinolo MA, Borges $M C$, De Castro IA, De Oliveira Pires IS, et al. Dietary glutamine supplementation increases the activity of peritoneal macrophages and hemopoiesis in early-weaned mice inoculated with Mycobacterium bovis bacillus Calmette-Guérin. J Nutr. 2008; 138(7):1343-8.

13. Ounsted M, Sleigh G. The infant's self-regulation of food intake and weight gain. Difference in metabolic balance after growth constraint or acceleration in utero. Lancet. 1975; 1(7922): 1393-7. doi: 10.1016/S0140-6736(75)92605-7.

14. Birch LL, Fisher JO. Development of eating behaviors among children and adolescents. Pediatrics. 1998; 101(3):539-48. doi: 10.1542/ peds.101.3.\$1.539.

15. Lucas A, Sarson DL, Blackburn AM, Adrian TE, Aynsley-Green A, Bloom SR. Breast vs bottle: endocrine responses are different with formula feeding. Lancet. 1980; 1(8181):1267-9. doi: 10.10 16/S0140-6736(80)91731-6.

16. Lucas A, Boyes S, Bloom SR, Aynsley-Green A. Metabolic and endocrine responses to a milk feed in six-day-old term infants: differences between breast and cow's milk formula feeding. Acta Paediatr Scand. 1981; 70(2):195-200. doi: 10.11 11/j.1651-2227.1981.tb05541.x.

17. Savino F, Fissore MF, Grassino EC, Nanni GE, Oggero R, Silvestro L. Ghrelin, leptin and IGF-I levels in breastfed and formula-fed infants in the first year of life. Acta Paediatr. 2005; 94(5):531-7. doi:_10.11 11/j.1651-2227.2005.tb01934.x.

18. Grosvenor CE, Picciano MF, Baumrucker CR. Hormones and growth factors in milk. Endocr Rev. 1993; 14(6):710-28. doi: 10.1210/edrv-14-6-710.

19. Hauner H, Rohrig K, Petruschke T. Effects of epidermal growth factor (EGF), platelet-derived growth factor (PDGF) and fibroblast growth factor (FGF) on human adipocyte development and function. Eur J Clin Invest. 1995; 25(2): 90-6. doi: 10.1111/j.1365-2362.1995.tb01532.x.

20. Casabiell X, Pineiro V, Tome MA, Peino R, Dieguez C, Casanueva FF. Presence of leptin in colostrum and/or breast milk from lactating mothers: a potential role in the regulation of neonatal food intake. J Clin Endocrinol Metab. 1997; 82(12): 4270-3. doi: 10.1210/jc.82.12.4270.

21. Bonomo IT, Lisboa PC, Passos MC, Alves SB, Reis AM, Moura EG. Prolactin inhibition at the end of lactation programs for a central hypothyroidism in adult rat. J Endocrinol. 2008; 198(2):331-7. doi: 10.1677/JOE-07-0505.

22. Bonomo IT, Lisboa PC, Pereira AR, Passos MC, de Moura EG. Prolactin inhibition in dams during lactation programs for overweight and leptin resistance in adult offspring. J Endocrinol. 2007; 192(2):339-44. doi: 10.1677/joe.1.06952.

23. Loizzo A, Loizzo S, Galietta G, Caiola S, Spampinato S, Campana G, et al. Overweight and metabolic and hormonal parameter disruption are induced in adult male mice by manipulations during lactation period. Pediatr Res. 2006; 59(1):111-5. doi: 10.1203/01.pdr.0000190575.12965.ce.

24. Picó C, Oliver P, Sánchez J, Miralles O, Caimari A, Priego $T$, et al. The intake of physiological doses of leptin during lactation in rats prevents obesity in later life. Int J Obes. 2007; 31(8):1199-209. doi: 10.1038/sj.ijo.0803585.

25. Attig L, Solomon G, Ferezou J, Abdennebi-Najar L, Taouis M, Gertler A, et al. Early postnatal leptin blockage leads to a long-term leptin resistance and susceptibility to diet-induced obesity in rats. Int J Obes. 2008; 32(7):1153-60. doi: 10.1038/ ijo.2008.39.

26. Toschke AM, Vignerova J, Lhotska L, Osancova K, Koletzko B, Von Kries R. Overweight and obesity in 6- to 14-year-old Czech children in 1991: protective effect of breast-feeding. J Pediatr. 2002; 141(6): 764-9. doi: 10.1067/mpd.2002.128890.

27. Kvaavik E, Tell GS, Klepp KI. Surveys of Norwegian youth indicated that breast feeding reduced subsequent risk of obesity. J Clin Epidemiol. 2005; 58(8):849-55. doi: 10.1016/j.jclinepi.2004.12.0 07.

28. Shields L, O'Callaghan M, Williams GM, Najman JM, Bor W. Breastfeeding and obesity at 14 years: a cohort study. J Paediatr Child Health. 2006; 42(5): 289-96. doi: 10.1111/j.1440-1754.2006.00864.x.

29. Li C, Goran MI, Kaur H, Nollen N, Ahluwalia JS. Developmental trajectories of overweight during childhood: role of early life factors. Obesity. 2007; 15(3): 760-71. doi: 10.1038/oby.2007.90.

30. Araújo CL, Victora CG, Hallal PC, Gigante DP. Breastfeeding and overweight in childhood: evidence from the Pelotas 1993 birth cohort study. Int J Obes. 2006; 30(3):500-6. doi: 10.1038/sj.ijo. 0803160.

31. Nelson MC, Gordon-Larsen P, Adair LS. Are adolescents who were breast-fed less likely to be overweight? Analysis of sibling pairs to reduce confounding. Epidemiology. 2005; 16(2):247-53. doi: 10.1097/01.ede.0000152900.81355.00. 
32. Hediger ML, Overpeck MD, Kuczmarski RJ, Ruan WJ. Association between infant breastfeeding and overweight in young children. JAMA. 2001; 285(19):2453-60. doi: 10.1001/jama.285.19.24 53.

33. Owen CG, Martin RM, Whincup PH, Davey-Smith G, Gillman MW, Cook DG. The effect of breastfeeding on mean body mass index throughout life: a quantitative review of published and unpublished observational evidence. Am J Clin Nutr. 2005; 82(6):1298-307.

34. Cope MB, Allison DB. Critical review of the World Health Organization's (WHO) 2007 report on 'evidence of the long-term effects of breastfeeding: systematic reviews and meta-analysis' with respect to obesity. Obes Rev. 2008; 9(6):594-605. doi: 10.1111/j.1467-789X.2008.00504.x.

35. Horta BL, Bahl R, Martinés JC, Victora CG. Evidence on the long-term effects of breastfeeding: systematic reviews and meta-analysis. World Health Organization. [cited 2009 Feb 6]. Available from: <http://whqlibdoc.who.int/publications/2007/ 9789241595230_eng.pdf>.

36. Reeves PG, Nielsen FH, Fahey GC Jr. Ain-93 purified diets for laboratory rodents: final report of the American institute of nutrition "ad hoc" writing committee on the reformulation of the AIN-76a rodent diet. J Nutr. 1993; 123(11):1939-51.
37. Dell RB, Holleran S, Ramakrishnan R. Sample Size Determination. ILAR J. 2002; 43(4): 207-13.

38. Goodwin JF, Murphy B, Guillemette M. Direct measurement of serum iron and binding capacity. Clin Chem. 1966; 12(2):47-57.

39. Doumas T. Albumin standards and measurement of serum albumin with bromocresol green. Clin Chim Acta. 1971; 31(1):87-96.

40. Lowry OH, Rosebruogh NJ, Farr AL, Randall RJ. Protein measurement with the Folin phenol reagent. J Biol Chem. 1951; 193(1):265-75.

41. Munro NN, Fleck $A$. The determination of nucleic acids. Methods Biochem Anal. 1966; 14: 113-76.

42. Gendimenico GJ, Bouquin PL, Tramposch KM. Diphenylamine-colorimetric method for DNA assay: a shortened procedure by incubating samples at 50 degrees C. Anal Biochem. 1988; 173(1):45-8.

43. Donato Jr J, Pedrosa RG, Cruzat VF, Pires IS, Tirapegui J. Effects of leucine supplementation on the body composition and protein status of rats submitted to food restriction. Nutrition. 2006; 22(5):520-7. doi: 10.1016/j.nut.2005.12.008.

44. Hedrich HJ, Bullock G. The laboratory mouse. Boston: Elsevier Academic Press; 2004.

Recebido em: 3/6/2008

Versão final reapresentada em: 2/3/2009 Aprovado em: 16/6/2009 
